\title{
A Kind of Microchannel Heat Sink Optimization for High Power Chips Based on CFD and Non-Silicon MEMS Technology
}

\author{
Dawei Yang ${ }^{1, \text { a }}$, Yan Wang ${ }^{2, b}$ Guifu Ding ${ }^{3, c}$ and Zhiyu Jin ${ }^{4, d}$ \\ ${ }^{123}$ School of Electronic Information and Electrical Engineering \\ Shanghai Jiao Tong University, Shanghai, China \\ adavidyoung2@sjtu.edu.cn, bwyyw@sjtu.edu.cn, ' guifuding@sjtu.edu.cn, \\ d115039910022@sjtu.edu.cn
}

Keywords: micro channel, heat sink, pin-fins, optimized

Abstract. A kind of distributed array structure micro channel heat sink is studied in this paper. The fluid height and the ratio between fluid and channel are optimized by computational fluid dynamics (CFD) thermal-mechanical coupling method. The typical heat sink is fabricated by UV-LIGA and non-silicon MEMS technology. The heat sink provides high performance of heat transfer capabilities with single inlet and outlet. The system is heated from top baseplate made of AlN, deionized water as a coolant and copper as the bottom baseplate. The best performance heat sink microchannel has a 300um square pin-fins and 200um fluid channel with a 500um gap height. The finally measurement shows that the heat sink that optimized can keep the chip below $56.3^{\circ} \mathrm{C}$ when heat flux is $243.81 \mathrm{~W} / \mathrm{cm}^{2}$, working fluid and environment is $20^{\circ} \mathrm{C}$ and a ratio of pumping power to heat rate of $0.18 \%$.

\section{Introduction}

With the development of IC manufacture procedure and package technology, very-large-scale integrated (VLSI) circuits are made smaller and smaller while the heat generation become larger and larger. Management of heat removal become a serious challenge[1]. If the heat flux generates from the chips can`t be removed in time. Temperature of chips will rise rapidly, when it run out of the working condition it will affect the stability of chips. Many thermal control techniques have been studied nowadays, such as natural-air convection forced-air convection cold plate technology liquid cooling technology two-phase transformation cooling technology thermoelectric cooling technology micro channel heat transfer technology and heat pipe technology. Although a heat flux under $100 \mathrm{~W} / \mathrm{cm}^{2}$ air cooling technology is enough[2]. But it`s inadequate for most applications nowadays. Because of the simple principle, easy processing technology, perfect performance and conveniently to make an array distribution microchannel heat sinks received a lot of attention and research.

Tuckerman and Pease first proposed the concept of microchannel heat sink in 1981, micro channels were etched in a silicon substrate with 50um width and 300um height and a heat flux of $790 \mathrm{w} / \mathrm{cm}^{2}$ could be removed with the maximum temperature rise of $71^{\circ} \mathrm{C}$ above the input water temperature[2]. After that, a lot of research was taken in the related fields. There are three major branches are investigated. Firstly the structures of the heat sinks are designed and optimized, for example, LUO et al[3] studied a honeycomb microchannel cooling system which with the characters of low-density combine a certain stiffness, strength, crushing energy absorption. John et al[4] focused on the different shapes of pin-fins to enhance the efficiency of the heat sink. In their paper six different shapes of pin-fins are arranged in a heat sink and was compared to the heat sink that without any pin-fin structures and made a weighted average method to determine a figure of merit for performance of each shape of pin-fin structure. Secondly reduce the characteristic dimension to add the conductivity of the heat sink. Tuckerman and Pease[2] compute the thermal resistance when IC substrate thinned to 100um and its back side is in intimate thermal contact with the heat exchanger, then the thermal resistance is only $0.007^{\circ} \mathrm{C} / \mathrm{W}$ for a $1-\mathrm{cm}^{2}$ circuit. Finally replace the working fluid of the heat sink, in order to increase the heat exchange efficiency. Jang al et[1] found that cooling performance would be enhanced $10 \%$ when Nano fluids containing diamond $(1 \mathrm{vol} \%$, $2 \mathrm{~nm})$ at the fixed pumping power of 2.25W. Yu al et[5] used Nano fluids containing 5.0vol\% graphene Nano 
sheets as cooling fluid and up to $86 \%$ increase in thermal conductivity. Most of the studies are concentrated on the physical parameters except the change of coolant, and lot of their researches only optimized one or two factors.

A kind of heat sink that could be used in fitting chips is studied in the paper. By comprehensive consideration, materials of the heat sink, fluid height, ratio of fluid and pin-fins are totally optimized. Finally a heat sink could be used single or array distribution is fabricated. In the test, a heat flux of $243.81 \mathrm{~W} / \mathrm{cm}^{2}$ at a surface temperature $56.3^{\circ} \mathrm{C}$ and a ratio of pumping power to heat rate of $0.18 \%$. The performance of the heat sink is very stability in the repeat test.

\section{Heat sink design and optimize \\ Heat sink design}
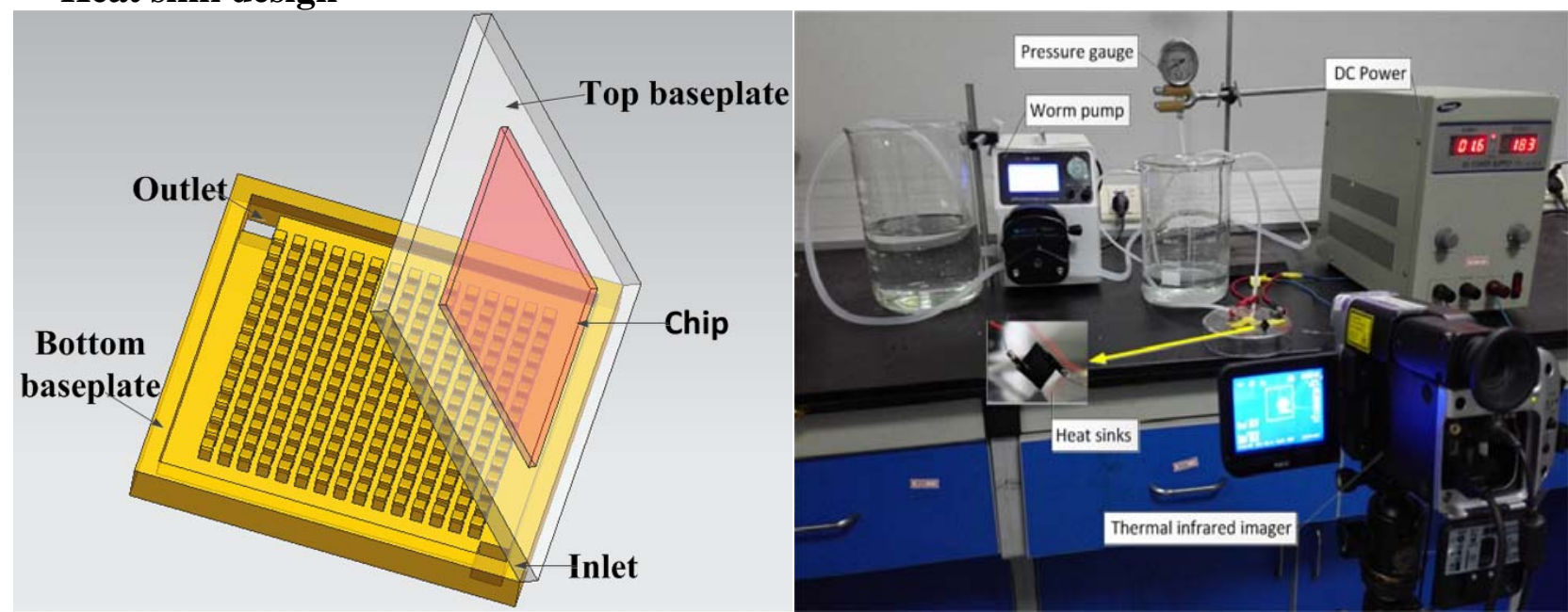

Fig.1 Schematic view of a pin-fin micro heat sink Fig.2 Schematic view of testing

Dimensions of ordinary chips is considered, a kind of heat sink with the length $1 \mathrm{~cm}$ and width $1 \mathrm{~cm}$ is designed as is shown in Fig.1. For the micro dimension, single inlet and outlet are designed at the corners along diagonal. Pin-fins with square geometry is used in the design. In the following optimization, several physical parameters are considered in order to find the best feature size.

\section{Governing equations}

The study in this paper assumes the flow is steady and laminar. The cooling fluid is deionized water, which is incompressible with homogeneous and constant thermal physical properties. The convective of air is set as $10 \mathrm{~W} /\left(\mathrm{m}^{2} * \mathrm{~K}\right)$ on the outer surfaces of the heat sink which contact with ambient air.

The temperature distribution within the geometry in this paper was described by solving the Equations. (1)-(3) which are respectively conservation of mass, momentum and energy Equations. The governing equations solved are listed as follows.

$$
\begin{aligned}
& \nabla * \vec{V}=0 . \\
& \rho(\vec{v} * \nabla \vec{v})=-\nabla \mathrm{P}+\mu \nabla^{2} \vec{v} . \\
& \rho_{f} C_{p f}(\vec{v} \cdot \nabla T)=K_{f} \nabla^{2} T .
\end{aligned}
$$

The energy equation for the solid parts:

$$
K_{S} \nabla^{2} T=0
$$

The heat flux between the interface of the water and the solid walls of heat sink is coupled and its continuity equation is given as:

$$
K_{S} \frac{\partial T}{\partial n}=K_{f} \frac{\partial T}{\partial n} \text {. }
$$


Where $\mathrm{v}$ is the velocity of the fluid in the heat sink, $\rho$ is the density of the fluid, $\nabla \mathrm{P}$ is the pressure difference between inlet and outlet, $\mu$ is the dynamic viscosity, $C_{p f}$ is the specific heat of the coolant. $K_{f}$ is the thermal conductivity of the fluid, while $K_{S}$ is the thermal conductivity of the solid parts.

For the optimization study in the paper, models were built on $\mathrm{GAMBIT}^{\mathrm{TM}}$, and were computed by FLUENT $^{\mathrm{TM}}$. The heat source is $72 \mathrm{~W}$, the coolant flow rate is set as $96 \mathrm{ml} / \mathrm{min}$ for no special note.

\section{Optimization of fluid height and ratio between channel and pin-fins}
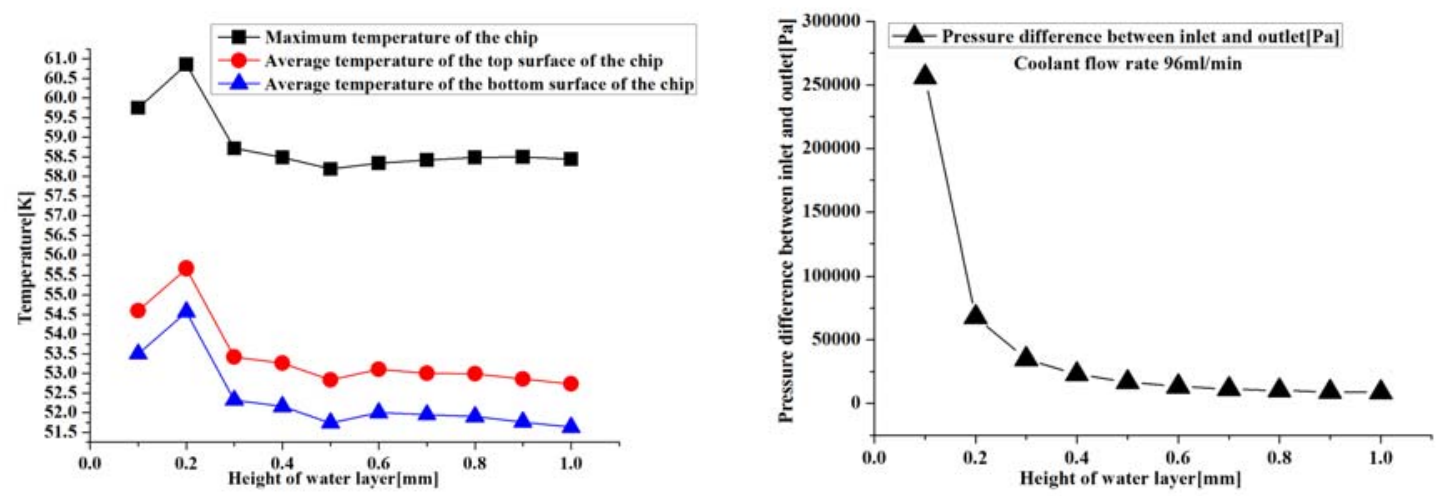

Figure.3Temperature of the chip with different water layer Figure.4Pressure difference between inlet and outlet

An important factor that can influence the performance of heat sink is the height of working fluid height. The height of deionized water will influent not only the pressure difference between inlet and outlet but also the thermal conductivity. With a low fluid height, the pressure difference will be very enormous, and the speed of the water in the channel is too high that could not make full heat exchange with heat sink. While the fluid height is too high, the top layer and the down layer temperature gradient will be very large, the heat sink can`t work efficiency. So we computed the height between $100 \mathrm{um}-1000 \mathrm{um}$, and make a scale of 100um as a unit. As is shown in Fig.3 when water layer height is $0.5 \mathrm{~mm}$ heat sink has the best performance, at the same time when water height is more than $0.5 \mathrm{~mm}$, pressure drop changes slowly as we can see in Fig.4. So $0.5 \mathrm{~mm}$ is chosen as the perfect design, for water height thermal conductivity is the best and the pressure difference changed little with the increase of fluid height.

\section{Optimization of the ratio between channel and pin-fins}

The size of the rectangle pin-fins and the width of the channel will directly influent the heat exchange area. So it`s a quiet important parameter to the heat sink. Combine with the precision of the UV-LIGA and the fact of the heat sink. 36 different kinds of ratio were designed as follows:

Table.1 Maximum temperature of chip top face with different ratio between channel and pin-fins

\begin{tabular}{lcccccc}
\hline $\begin{array}{l}\text { Edge length [um] } \\
\text { Channel width [um] }\end{array}$ & 150 & 200 & 250 & 300 & 350 & 400 \\
\hline 150 & $330.56 \mathrm{~K}$ & $331.19 \mathrm{~K}$ & $330.21 \mathrm{~K}$ & $329.30 \mathrm{~K}$ & $332.23 \mathrm{~K}$ & $332.79 \mathrm{~K}$ \\
200 & $332.14 \mathrm{~K}$ & $331.31 \mathrm{~K}$ & $331.07 \mathrm{~K}$ & $329.06 \mathrm{~K}$ & $333.75 \mathrm{~K}$ & $332.94 \mathrm{~K}$ \\
250 & $332.50 \mathrm{~K}$ & $331.87 \mathrm{~K}$ & $331.54 \mathrm{~K}$ & $330.41 \mathrm{~K}$ & $333.89 \mathrm{~K}$ & $332.63 \mathrm{~K}$ \\
300 & $334.47 \mathrm{~K}$ & $333.61 \mathrm{~K}$ & $332.75 \mathrm{~K}$ & $331.25 \mathrm{~K}$ & $335.09 \mathrm{~K}$ & $332.64 \mathrm{~K}$ \\
350 & $335.56 \mathrm{~K}$ & $334.41 \mathrm{~K}$ & $334.84 \mathrm{~K}$ & $332.83 \mathrm{~K}$ & $335.73 \mathrm{~K}$ & $333.84 \mathrm{~K}$ \\
400 & $337.07 \mathrm{~K}$ & $342.58 \mathrm{~K}$ & $335.76 \mathrm{~K}$ & $333.58 \mathrm{~K}$ & $336.59 \mathrm{~K}$ & $335.33 \mathrm{~K}$ \\
\hline
\end{tabular}


As is showed in table1, when the edge of pin-fins is 300um, and the width of fluid channel is 200um. The maximum temperature of chip is $329.30 \mathrm{~K}$. So the ratio was chosen for the heat sink.

\section{Fabrication and test}

Heat sink combines three parts: top baseplate which made of AlN with a heat film, bottom baseplate which made of copper with pin-fins and drain piper which made of copper. Top baseplate and bottom baseplate are bonded together, then drain piper fixed on the inlet and outlet.

Peristaltic pump (NewKing BG-600) provides the steady water flow. Flow rate is controlled from $30 \mathrm{ml} / \mathrm{min}$ to $90 \mathrm{ml} / \mathrm{min}, 30 \mathrm{ml} / \mathrm{min}$ is set as a unit. A heat film is used to imitate the working chip, heating power range from 0 to $243.81 \mathrm{~W}$ in the test. Under a steady flow rate, heating power is added, and the maximum temperature is recorded, all the equipments are combined together as Fig.2 shows.

\section{Results and conclusion}

In order to prove the reasonable of the design. Two typical heat sinks are fabricated, the optimized one(Edge lenth 300um, channel width 200um) and a different ratio one (Edge length 200um, channel width 300um) we mark them ID No.32 and No.23 separately.
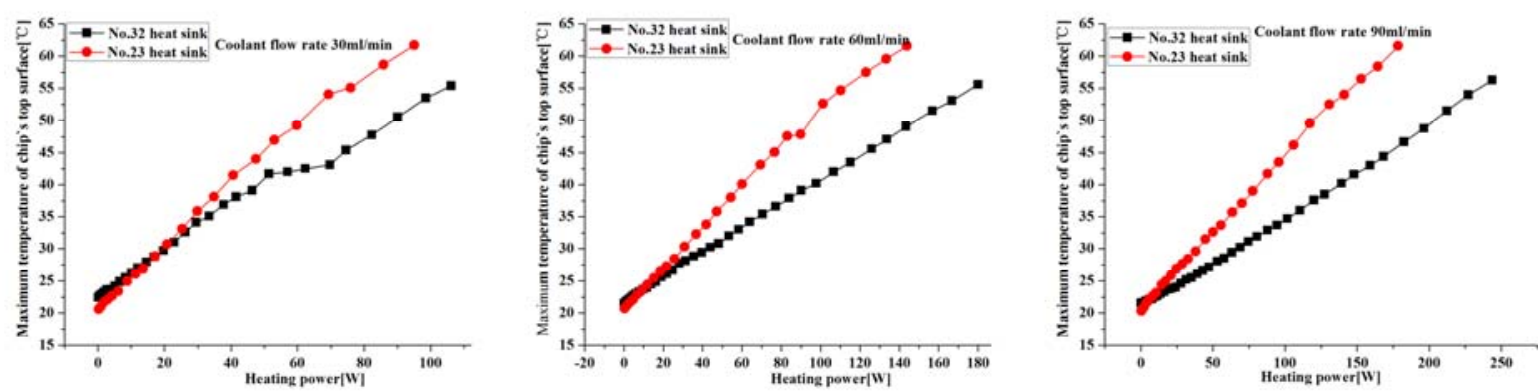

Fig.5 Heat sinks` performance contrast with different coolant flow rate

As is shown in figure5 heat sink No.32 and No.23 were tested in different flow rate range from $30 \mathrm{ml} / \mathrm{min}$ to $90 \mathrm{ml} / \mathrm{min}$. The performance of No.32 is obviously better than the No.23 when coolant flow rate increase.

Two main parameters are optimized: fluid height and ratio between channel and pin-fins. The heat transfer capabilities of the heat sink improved a lot especially in coolant flow rate increase. In the measurement a heat flux of $243.81 \mathrm{~W} / \mathrm{cm} 2$ reached at flow rate of $90 \mathrm{ml} / \mathrm{min}$, when the maximum temperature of chip is $56.3^{\circ} \mathrm{C}$ and coolant is $20^{\circ} \mathrm{C}$.

\section{References}

[1] Jang S.P.,Choi S.U.S.: 'Cooling Performance of a Microchannel Heat Sink with Nanofluids', Appl Therm Eng, 2006, 26, pp. 2457-2463

[2] TUCKERMAN D.B.,PEASE R.F.W.: 'High-Performance Heat Sinking for Vlsi', IEEE Electron Device Letter, 1981, 2, pp. 126-129

[3] Luo X., Liu Y.,Liu W.: 'A Honeycomb Microchannel Cooling System for Microelectronics Cooling', Heat Transfer Eng, 2011, 32, pp. 616-623

[4] T.J.John, B.Mathew,H.Hegab: 'Characteristic Study on the Optimization of Pin-Fin Micro Heat Sink', ASME 2009 International Mechanical Engineering Congress \& Exposition, 2009,

[5] Yu W., Xie H., Wang X.,Wang X.: 'Significant Thermal Conductivity Enhancement for Nanofluids Containing Graphene Nanosheets', Phys Lett A, 2011, 375, pp. 1323-1328 